\title{
Thermochemical stability of silicon-oxygen-carbon alloy thin films: A model system for chemical and structural relaxation at $\mathrm{SiC}-\mathrm{SiO}_{2}$ interfaces
}

\author{
D. M. Wolfe, B. J. Hinds, F. Wang, G. Lucovsky, ${ }^{\text {a) }}$ B. L. Ward, M. Xu, R. J. Nemanich, \\ and D. M. Maher \\ Departments of Materials Science and Engineering, Physics, and Electrical and Computer Engineering, \\ North Carolina State University, Raleigh, North Carolina 27695-7907
}

(Received 1 February 1999; accepted 29 March 1999)

\begin{abstract}
Alloy thin films of hydrogenated silicon-oxygen-carbon $(\mathrm{Si}, \mathrm{C}) \mathrm{O}_{x} x<2$, were deposited and analyzed in terms of changes in structure and bonding as a function of rapid thermal annealing between 600 and $1100{ }^{\circ} \mathrm{C}$ using a combination of Fourier transform infrared spectroscopy, Raman scattering and high-resolution transmission electron microscopy. Results showed that three structural/chemical transformations took place upon annealing. The initial reaction $\left(600-800{ }^{\circ} \mathrm{C}\right)$ involved the loss of hydrogen bonded to both silicon and carbon. At intermediate temperatures $\left(900-1000^{\circ} \mathrm{C}\right)$ a $\mathrm{Si}-\mathrm{O}-\mathrm{C}$ type bond was observed to form, and subsequently disappear after annealing to $1050{ }^{\circ} \mathrm{C}$. The formation of ordered amorphous-SiC regions, nanocrystalline-Si regions, and stoichiometric, thermally relaxed $\mathrm{SiO}_{2}$ accompanied the disappearance of the $\mathrm{Si}-\mathrm{O}-\mathrm{C}$ bond at the $1050{ }^{\circ} \mathrm{C}$ annealing temperature. Using this alloy as a model system, important information is obtained for optimized processing of $\mathrm{SiC}^{-\mathrm{SiO}_{2}}$ interfaces for device applications. (C) 1999 American Vacuum Society. [S0734-2101(99)16104-9]
\end{abstract}

\section{INTRODUCTION}

The attainment of a low defect density gate oxide on $\mathrm{SiC}$ substrates is critically important in optimizing the electrical performance of field effect transistor devices. In particular, the interface between the substrate and the gate oxide plays a key role in determining transistor performance characteristics and reliability.

Considering first the $\mathrm{Si}-\mathrm{SiO}_{2}$ interfaces, studies based on x-ray photoelectron spectroscopy (XPS) of $\mathrm{Si}-\mathrm{SiO}_{2}$ interfaces prior to postoxidation annealing have identified an interfacial compositional transition layer within $0.5 \mathrm{~nm}$ of the interface which contains intermediate oxidation states of $\mathrm{Si}$, i.e., $\mathrm{Si}^{1+}, \mathrm{Si}^{2+}$, and $\mathrm{Si}^{3+}$ or suboxide $\left(\mathrm{SiO}_{x}, x<2\right) .{ }^{1-3}$ This transition region can contribute to interface roughness and also give rise to electronically active defects. Improvement of device properties is typically achieved following a postoxidation anneal. ${ }^{4}$ Analysis of interface bonding chemistry and structure has shown that the improvements after annealing derive from reductions of suboxide bonding groups in interfacial transition regions, effectively smoothing the $\mathrm{Si}-\mathrm{SiO}_{2}$ interface. ${ }^{4-13}$

Studies of $\mathrm{SiC}-\mathrm{SiO}_{2}$ interfaces have also identified an interfacial compositional transition layer. ${ }^{14-16}$ Depending on the substrate polytype, oxidation temperature, and ambient (wet versus dry), results have shown that carbon atoms may become trapped in the growing oxide as they outdiffuse from the interface, forming an oxycarbide interface layer. For example, Hornetz, Michel, and Halbritter have shown ${ }^{14}$ using angle resolved XPS that a thin layer $(1 \mathrm{~nm})$ with an approximate composition $\mathrm{Si}_{4} \mathrm{O}_{2} \mathrm{C}_{4-x}(x<2)$ exists at the $\mathrm{SiC}-\mathrm{SiO}_{2}$ interface, and that graphite may be present on the top surface

${ }^{a)}$ Electronic mail: gerry_lucovsky@ncsu.edu of the oxide. Using Auger electron spectroscopy (AES) Chaudhry ${ }^{15}$ reported carbon contents in wet oxides grown on $3 \mathrm{C}-\mathrm{SiC}$ as high as $14 \%$, and that dry oxides contained much more silicon than stoichiometric $\mathrm{SiO}_{2}$, i.e., suboxide character, indicating that wet and dry oxidation differ in mechanism considerably for $3 \mathrm{C}-\mathrm{SiC}$. The effect of carbon in the oxide and the reported nonstoichiometric suboxide on the electrical performance of $\mathrm{SiC}$ metal-oxide-semiconductor field effect transistor devices is unknown. Transistor characteristics following various postoxidation annealing treatments have been reported by Lipkin and Palmour, ${ }^{17}$ with improvements being noted in interface trap density and electron mobility. The effect of this postoxidation anneal, however, is not well understood microscopically. Therefore, a fundamental understanding of the bonding environment when carbon is incorporated into the oxide and its effect on suboxide formation is needed, especially in light of (i) the numerous substrate polytypes, (ii) the speculation regarding oxidation mechanisms, ${ }^{18}$ and (iii) room temperature channel electron mobility values which are substantially lower than those measured in the bulk. ${ }^{17}$

This article extends studies of the thermal stability of plasma-deposited $\mathrm{SiO}_{x}$ thin films ${ }^{19-21}$ to suboxides of $\mathrm{Si}$ and $\mathrm{C},(\mathrm{Si}, \mathrm{C}) \mathrm{O}_{x}$. The research identifies changes in structure and bonding using Fourier transform infrared spectroscopy (FTIR), Raman scattering, and high-resolution transmission electron microscopy (TEM), as a function of rapid thermal annealing (RTA) temperatures that are of importance for understanding changes in interface bonding and chemistry occurring during the thermal oxidation of $\mathrm{SiC}$ and subsequent annealing of the $\mathrm{SiC}-\mathrm{SiO}_{2}$ interfaces. In particular, a $\mathrm{Si}-$ $\mathrm{O}-\mathrm{C}$ type bonding group is identified to form in the films between 900 and $1000{ }^{\circ} \mathrm{C}$ annealing temperature, and subsequently disappear at $1050{ }^{\circ} \mathrm{C}$. The results of this research 
then provide important information under pinning $\mathrm{SiC}$ device processing technology.

\section{EXPERIMENT}

Thin films of hydrogenated $(\mathrm{Si}, \mathrm{C}) \mathrm{O}_{x}$ approximately 200 $\mathrm{nm}$ in thickness were deposited on fused quartz and high resistivity $(15 \Omega \mathrm{cm})$-type $\mathrm{Si}$ wafers in an ultrahigh vacuum (UHV) multichamber system using a remote plasma enhanced chemical vapor deposition (RPECVD) process, as described elsewhere. ${ }^{22}$ The fused quartz substrates were used for Raman studies to eliminate spectral interference from a crystalline-Si substrate peak. For FTIR analysis, high resistivity $\mathrm{Si}$ wafers were used to minimize free-carrier absorption in the substrate. The wafers were also single side polished and "orange peel" roughened on the other side to minimize multiple reflections in the substrate and reduce background interference fringes.

Prior to sample insertion into the load lock of the deposition system, (i) a $15 \mathrm{~s} \mathrm{HF}$ dip (50:1) followed by (ii) a $1 \mathrm{~min}$ deionized water rinse and (iii) nitrogen blow dry were performed on the Si wafers. A $10 \mathrm{~min}$ ultrasonic bath in a sulfuric/chromic acid glass cleaning solution followed by (i) a 10 min deionized water rinse and (ii) a nitrogen blow dry was done on the fused quartz. Films of $(\mathrm{Si}, \mathrm{C}) \mathrm{O}_{x}$ were deposited at $250{ }^{\circ} \mathrm{C}$ and 300 mTorr using (i) excited species (e.g., $\mathrm{O}_{2}^{*}$ and $\mathrm{O}$ atoms) transported out of an upstream $\mathrm{He} / \mathrm{O}_{2}$ radio frequency plasma, and (ii) neutral species from downstream injected $\mathrm{SiH}_{4} / \mathrm{CH}_{4}$ mixtures. ${ }^{23}$ Alloy compositions for the films were determined by XPS and Rutherford backscattering (RBS). The composition of the $(\mathrm{Si}, \mathrm{C}) \mathrm{O}_{x}$ films was; $x$ $\sim 0.15$ and $\mathrm{C} \sim 10$ at. \%, with an uncertainty of \pm 0.02 at. $\%$. For baseline reference and comparison, thin films of hydrogenated $\mathrm{SiO}_{x}, x \sim 0.15$ and $\mathrm{SiC}_{x}, x \sim 0.2$, were also prepared by similar RPECVD processes. The local bonding environments and structure in these three different types of alloy films was studied using a combination of FTIR, Raman, and high-resolution TEM, as a function of RTA temperatures between 600 and $1100{ }^{\circ} \mathrm{C}$. Characterization was performed before and after direct annealing to the desired temperature at a ramp rate of $100{ }^{\circ} \mathrm{C} / \mathrm{s}$ in $1 \mathrm{~atm}$ Ar for $90 \mathrm{~s}$. For FTIR analysis, spectra were subtracted from a reference $\mathrm{Si}$ wafer. ${\mathrm{An} \mathrm{Ar}^{+}}^{+}$laser operating at $514.53 \mathrm{~nm}$, with incident laser power on the sample of approximately $150 \mathrm{~mW}$, was used for Raman scattering analysis. High-resolution TEM imaging was performed on cross-sectional samples, prepared using standard cutting and polishing techniques, in the bright-field mode with an accelerating voltage of $250 \mathrm{kV}$.

\section{EXPERIMENTAL RESULTS}

\section{A. $\mathrm{SiO}_{x}$ baseline}

Figure 1 shows FTIR absorption spectra before and after annealing to various temperatures for $\mathrm{SiO}_{x}(x \sim 0.15)$ thin films. Three distinct spectral features are noted and shift upon annealing. The peak of $630 \mathrm{~cm}^{-1}$ is a $\mathrm{Si}-\mathrm{H}$ bending mode $^{24}$ and is a result of hydrogen incorporation $(\sim 15$ at. \%) into the growing film from the source gas $\mathrm{SiH}_{4}$. Upon an-

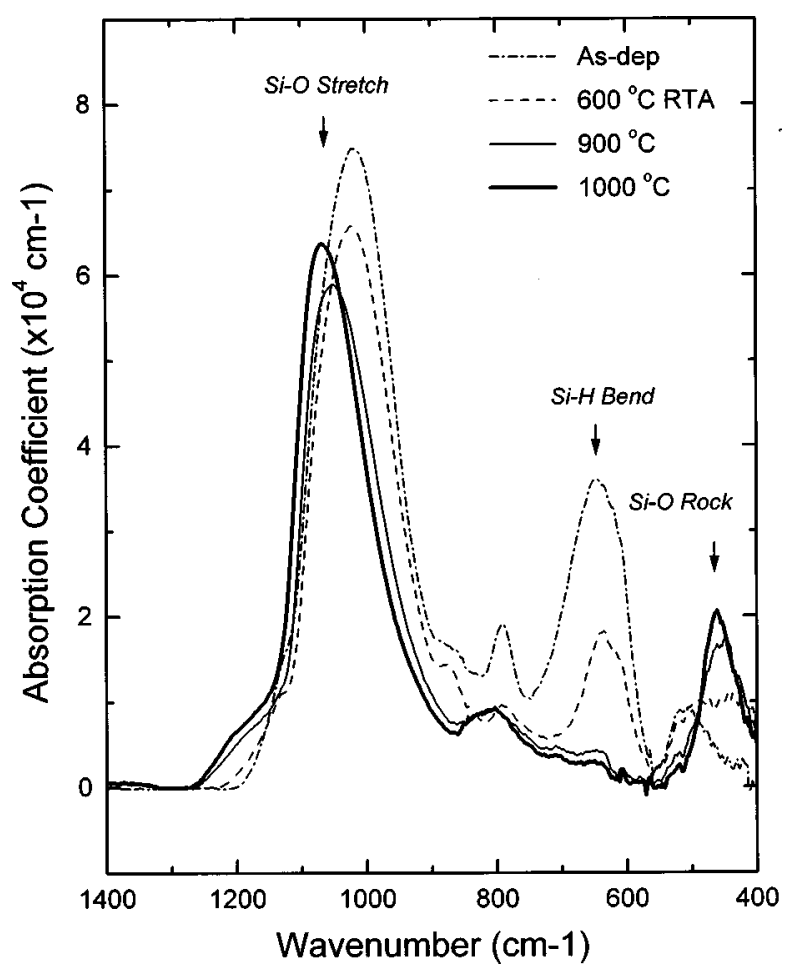

FIG. 1. FTIR absorption spectra of $\mathrm{SiO}_{x},(x \sim 0.15)$ thin films before and after annealing.

nealing to temperatures greater than about $800{ }^{\circ} \mathrm{C}$ this feature completely disappears, demonstrating the initial reaction upon annealing to temperatures of about $600{ }^{\circ} \mathrm{C}$ involves the loss of bonded hydrogen to silicon from the films. The decrease in the infrared peak at $630 \mathrm{~cm}^{-1}$ is accompanied by a similar decrease in a coupled $\mathrm{Si}-\mathrm{O}-\mathrm{Si}-\mathrm{H}$ vibration at 780 $\mathrm{cm}^{-1} \cdot{ }^{24}$ Once hydrogen is lost, this feature is replaced by a $\mathrm{Si}-\mathrm{O}$ bond bending mode at $\sim 810 \mathrm{~cm}^{-1}$. The intense peak in between $1015-1080 \mathrm{~cm}^{-1}$ is the $\mathrm{Si}-\mathrm{O}$ bond stretching mode. ${ }^{24}$ In the as-deposited films, this $\mathrm{Si}-\mathrm{O}$ stretching mode is located at $\sim 1017 \mathrm{~cm}^{-1}$, indicative of suboxide bonding arrangements. ${ }^{6,19,24}$ As the annealing temperature is increased the $\mathrm{Si}-\mathrm{O}$ stretching mode shifts towards higher frequencies, signifying that atomic rearrangement is occurring and that suboxide bonding is being reduced. This feature becomes characteristic of stoichiometric and thermally relaxed $\mathrm{SiO}_{2}$ (Refs. 6,13) after annealing to approximately $900{ }^{\circ} \mathrm{C}$. The third distinguishing $\mathrm{Si}-\mathrm{O}$ feature is the $\mathrm{Si}-\mathrm{O}$ bond rocking mode located at $\sim 440 \mathrm{~cm}^{-1}$. This mode becomes pronounced after annealing to approximately $900{ }^{\circ} \mathrm{C}$, and again is characteristic of stoichiometric and thermally relaxed $\mathrm{SiO}_{2}$.

Figure 2 shows Raman spectra of $\mathrm{SiO}_{x}, x \sim 0.15$ thin films before and after annealing to various temperatures. The spectra for the as-deposited films indicated that they were amorphous and were not compositionally homogeneous. A transverse acoustic phonon mode at $150 \mathrm{~cm}^{-1}$ was observed, indicating that amorphous-Si $(a-\mathrm{Si})$ regions were present. The onset of nanocrystalline- $\mathrm{Si}(\mathrm{nc}-\mathrm{Si})$ formation in the films was observed in the spectra by the emergence of an optical 


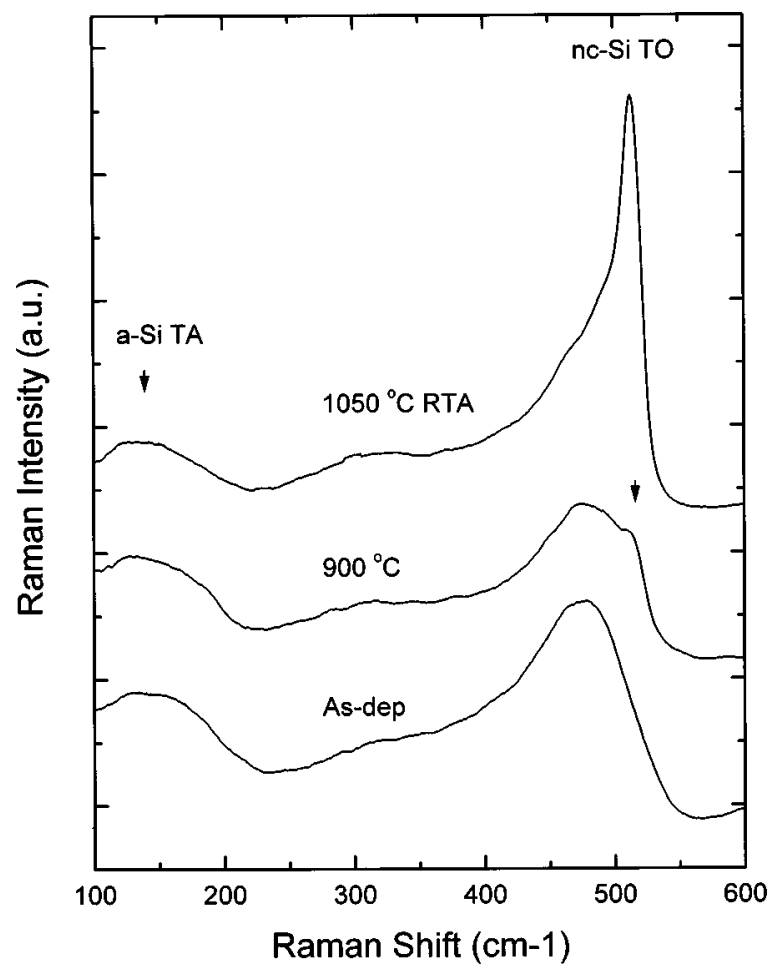

FIG. 2. Raman scattering spectra of $\mathrm{SiO}_{x},(x \sim 0.15)$ thin films before and after annealing.

phonon mode at $515 \mathrm{~cm}^{-1}$. In Fig. 2, this feature is just becoming observable after annealing at $900{ }^{\circ} \mathrm{C}$ and is clearly pronounced after annealing to $1050^{\circ} \mathrm{C}$.

Consistent with Raman analysis, Fig. 3 shows a digitally enhanced, high-resolution TEM image of a $\mathrm{SiO}_{x}$ film, $x$ $\sim 0.15$ after annealing to $900{ }^{\circ} \mathrm{C}$. Randomly oriented Si crystallites, as verified through selective area diffraction, were observed to form through out the films, with their size increasing as the annealing temperature was increased. The

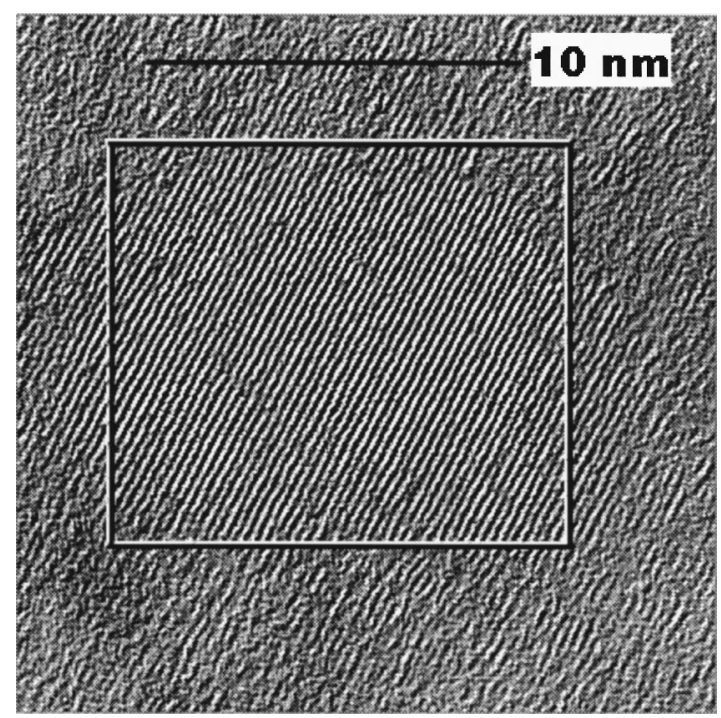

FIG. 3. High-resolution TEM image of a $\mathrm{SiO}_{x},(x \sim 0.15)$ thin film after annealing to $900{ }^{\circ} \mathrm{C}$.

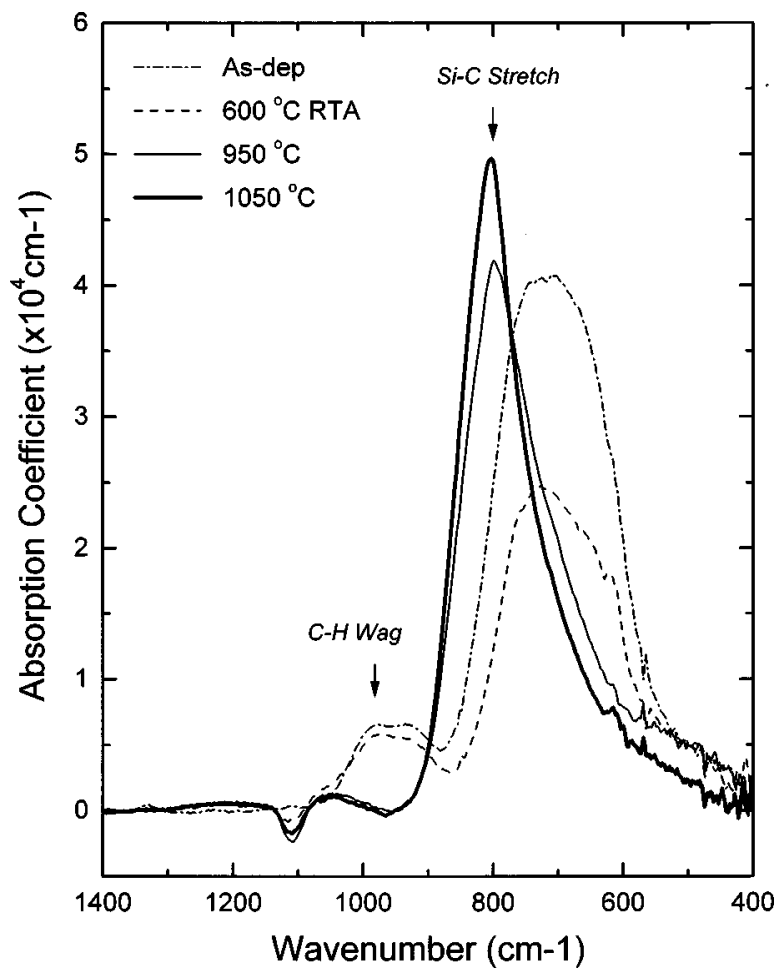

FIG. 4. FTIR absorption spectra of $\mathrm{SiC}_{x},(x \sim 0.2)$ thin films before and after annealing.

size of the crystallites that formed after annealing to $900{ }^{\circ} \mathrm{C}$ was approximately $10 \mathrm{~nm}$. The box in Fig. 3 outlines a typical Si crystallite.

In summary, the significant bonding and morphology changes that occur between as-deposited films and films annealed at $900{ }^{\circ} \mathrm{C}$ correspond to the formation of stoichiometric and structurally relaxed $\mathrm{SiO}_{2}$ regions (from FTIR analysis) and nanocrystalline-Si regions (from Raman and TEM analysis).

\section{B. $\mathrm{SiC}_{x}$ baseline}

Figure 4 shows FTIR spectra before and after rapid thermal annealing to various temperatures for $\mathrm{SiC}_{x}$ thin films, $x \sim 0.2$. Analysis of the spectra shows that the initial reaction involves the loss of hydrogen bonded to silicon and carbon. The modes between 900 and $1000 \mathrm{~cm}^{-1}$ are due to $\mathrm{C}-\mathrm{H}$ bond wagging motions $\mathrm{s}^{25}$ and disappear above $700{ }^{\circ} \mathrm{C}$ annealing temperature. The intensity of the $\mathrm{Si}-\mathrm{H}$ bending mode at $630 \mathrm{~cm}^{-1}$ drops sharply after annealing above $800{ }^{\circ} \mathrm{C}$. A $\mathrm{Si}-\mathrm{CH}$ bond wagging mode,${ }^{25}$ which is present in the same vicinity as the $\mathrm{Si}-\mathrm{H}$ bending mode, and very weak $\mathrm{Si}-\mathrm{CH}$ bond bending mode ${ }^{25}$ present at about $1340 \mathrm{~cm}^{-1}$ both decrease upon annealing to about $800{ }^{\circ} \mathrm{C}$. Most evident in the spectra is the appearance of a relatively narrow $\mathrm{Si}-\mathrm{C}$ bond stretching mode located at $800 \mathrm{~cm}^{-1}$ after annealing to $950{ }^{\circ} \mathrm{C}$. Further increases in annealing temperature shift this mode towards higher frequencies, indicating increased $\mathrm{C}$ to Si coordination. ${ }^{26}$

Figure 5 shows Raman spectra before and after annealing to various temperatures for $\mathrm{SiC}_{x}$ thin films, $x \sim 0.2$. The as- 


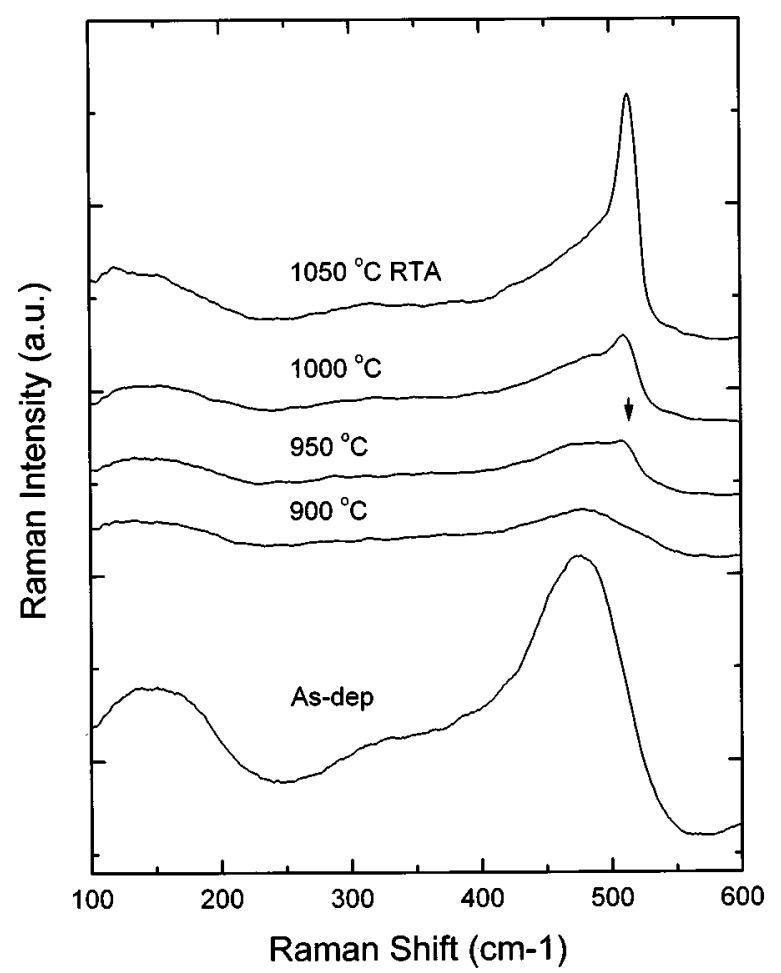

FIG. 5. Raman scattering spectra of $\mathrm{SiC}_{x},(x \sim 0.2)$ thin films before and after annealing.

deposited films were amorphous and compositionally inhomogeneous, as similarly shown for the $\mathrm{SiO}_{x}$ films above. Also, as in the case for the $\mathrm{SiO}_{x}$ films, Raman spectra of the $\mathrm{SiC}_{x}$ films show that $\mathrm{Si}$ crystallization occurs after high temperature annealing. As shown in Fig. 5, the feature at 515 $\mathrm{cm}^{-1}$ represents the formation of nanocrystalline-Si regions, and occurs after annealing to approximately $950{ }^{\circ} \mathrm{C}$. Note that no other phonon modes of any other crystalline phases such as $\mathrm{SiC}$ were observed. For example, for all of the crystalline $\mathrm{SiC}$ polytypes, both the transverse and longitudinal optical phonon ${ }^{27}$ modes occur at between 780 and $980 \mathrm{~cm}^{-1}$ and were not detected. Also, neither crystalline nor amorphous carbon-carbon vibrations were detected. Highresolution TEM imaging (not shown) is consistent with these results, and in particular, no crystalline phases other than silicon were observed in the selective area diffraction patterns.

In summary, the significant bonding and morphology changes that occur between as-deposited films and films annealed at $950{ }^{\circ} \mathrm{C}$ correspond to the formation of chemically ordered $a$-SiC regions (from FTIR analysis) and nanocrystalline-Si regions (from Raman and TEM analysis).

\section{C. $(\mathrm{Si}, \mathrm{C}) \mathrm{O}_{x}$}

After establishing baseline reference results for $\mathrm{SiO}_{x}$ and $\mathrm{SiC}_{x}$ films, results are now presented for films in which $\mathrm{CH}_{4}$ has been added to the $\mathrm{Si}$ suboxide source gas mix of $\mathrm{SiH}_{4}$ and $\mathrm{O}_{2}$ to form $(\mathrm{Si}, \mathrm{C}) \mathrm{O}_{x}$ alloys. Figure 6 shows FTIR spectra before and after annealing of $(\mathrm{Si}, \mathrm{C}) \mathrm{O}_{x}$ films, $x \sim 0.15$ and $\mathrm{C} \sim 10$ at. \%. As shown in Fig. 6, the spectra are essentially a

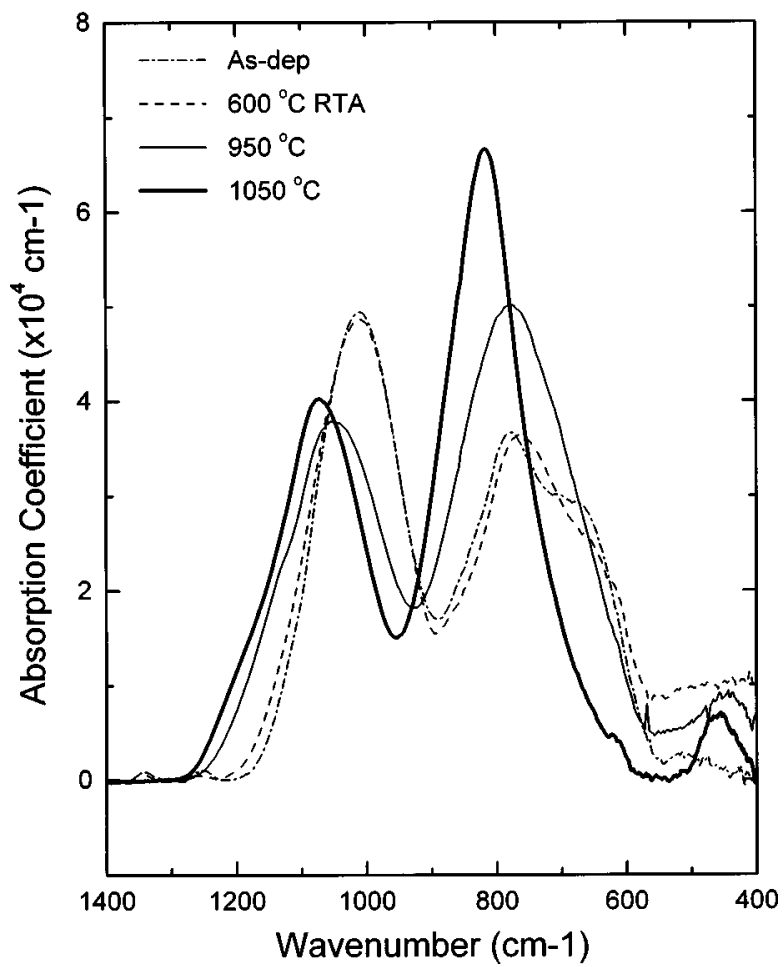

FIG. 6. FTIR absorption spectra of $(\mathrm{Si}, \mathrm{C}) \mathrm{O}_{x},(x \sim 0.15$ and $\mathrm{C} \sim 10$ at. \%) thin films before and after annealing.

combination of the $\mathrm{SiO}_{x}$ and $\mathrm{SiC}_{x}$ spectra, however, with several important and subtle differences. For these films, the initial thermally driven annealing reaction also involved the loss of bonded hydrogen from both $\mathrm{Si}-\mathrm{H}$ and $\mathrm{C}-\mathrm{H}$ groups, as explained above for $\mathrm{SiC}_{x}$ films. A well defined $\mathrm{Si}-\mathrm{C}$ bond stretching mode located at $800 \mathrm{~cm}^{-1}$ emerges in the $(\mathrm{Si}, \mathrm{C}) \mathrm{O}_{x}$ spectra, but after annealing to $1050^{\circ} \mathrm{C}$ rather than $950{ }^{\circ} \mathrm{C}$, as for the $\mathrm{SiC}_{x}$ films. Further increases in annealing temperature again shift this mode towards higher frequencies, indicating increased $\mathrm{C}$ to $\mathrm{Si}$ coordination. ${ }^{26}$ Similar to the $\mathrm{SiO}_{x}$ films, in the as-deposited $(\mathrm{Si}, \mathrm{C}) \mathrm{O}_{x}$ films, the $\mathrm{Si}-\mathrm{O}$ stretching mode is initially located at $1015 \mathrm{~cm}^{-1}$, indicative of suboxide bonding arrangements. As the annealing temperature is increased the $\mathrm{Si}-\mathrm{O}$ stretch mode shifts towards higher frequencies, signifying that atomic rearrangement is occurring and that suboxide bonding is being reduced. However, at approximately $900{ }^{\circ} \mathrm{C}$ a shoulder located at $\sim 1125 \mathrm{~cm}^{-1}$ is observed to form on the high frequency side of the $\mathrm{Si}-\mathrm{O}$ stretch mode, and is attributed to $\mathrm{Si}-\mathrm{O}-\mathrm{C}$ bonding groups ${ }^{25,28,29}$ on the basis of its frequency relative to the $\mathrm{Si}-\mathrm{O}-\mathrm{Si}$ stretch mode. In the $\mathrm{Si}-\mathrm{O}-\mathrm{C}$ bonding group, oxygen is the bridging atom between $\mathrm{Si}-\mathrm{O}_{4}$ and $\mathrm{O}-\mathrm{Si}-\mathrm{C}_{3}$ tetrahedra. This feature is not observed after annealing to $1050{ }^{\circ} \mathrm{C}$, and stoichiometric, thermally relaxed $\mathrm{SiO}_{2}$ is formed. The implications of this added feature in the spectra will be addressed in Sec. IV.

Figure 7 shows Raman spectra before and after annealing of (Si,C, $\mathrm{O}_{x}$ ) films, $x \sim 0.15$ and $\mathrm{C} \sim 10$ at. \%. Again, the films were amorphous and compositionally inhomogeneous, as deduced for the $\mathrm{SiO}_{x}$ and $\mathrm{SiC}_{x}$ films. After annealing to approximately $1050{ }^{\circ} \mathrm{C}$, and as shown in Fig. 7, a feature at 513 


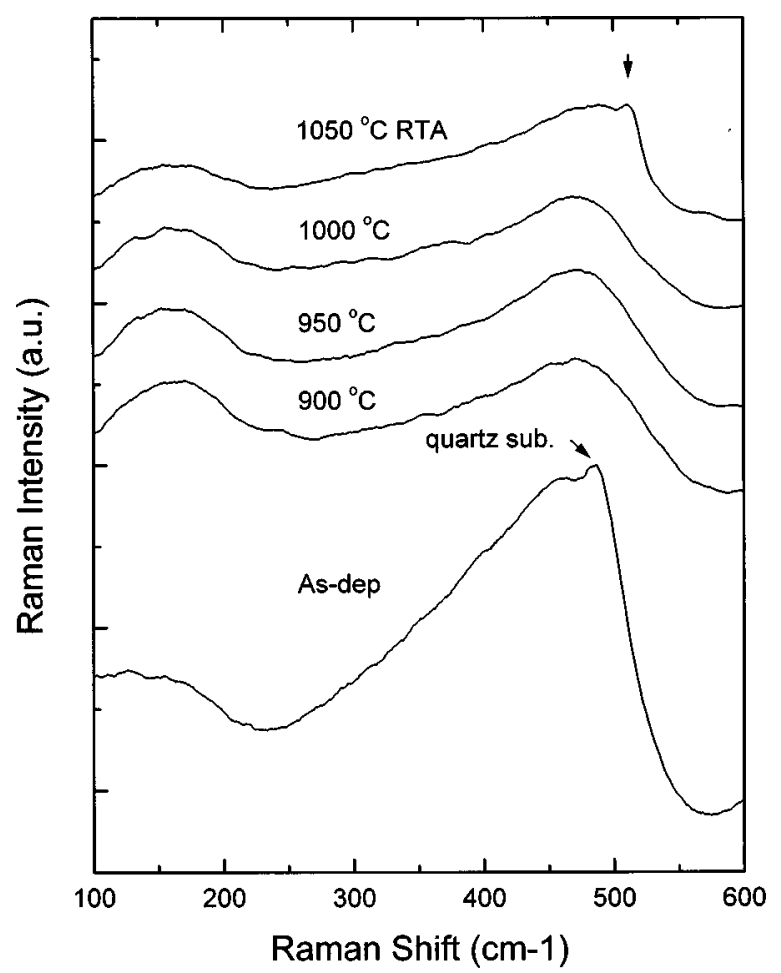

Fig. 7. Raman scattering spectra of $(\mathrm{Si}, \mathrm{C}) \mathrm{O}_{x},(x \sim 0.15$ and $\mathrm{C} \sim 10$ at. $\%)$ thin films before and after annealing.

$\mathrm{cm}^{-1}$ represents the formation of nanocrystalline-Si regions. As with the $\mathrm{SiC}_{x}$ films, no other phonon modes of crystalline phases were detected, indicating that crystalline regions of $\mathrm{SiC}$ or $\mathrm{C}$ were not formed. Note that the peak in the asdeposited spectra at $490 \mathrm{~cm}^{-1}$ is due to the quartz substrate.

Figure 8 shows a digitally enhanced, high-resolution TEM image of $(\mathrm{Si}, \mathrm{C}) \mathrm{O}_{x}$ films, $x \sim 0.15$ and $\mathrm{C} \sim 10$ at. \% after annealing to $1050{ }^{\circ} \mathrm{C}$. Consistent with Raman analysis, only randomly oriented crystallites of $\mathrm{Si}$ were observed to form

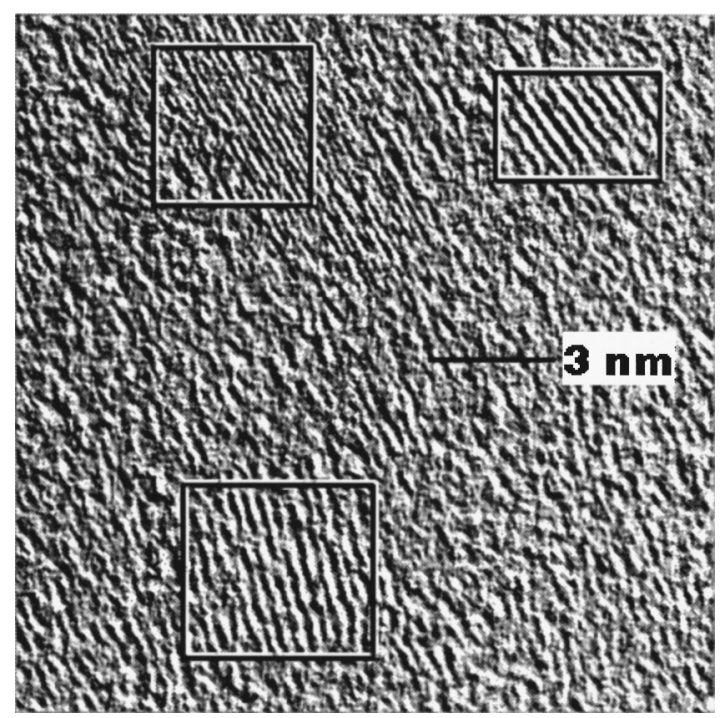

FIG. 8. High-resolution TEM image of a $(\mathrm{Si}, \mathrm{C}) \mathrm{O}_{x}, \quad(x \sim 0.15$ and $\mathrm{C} \sim 10$ at. \%) thin film after annealing to $1050^{\circ} \mathrm{C}$.

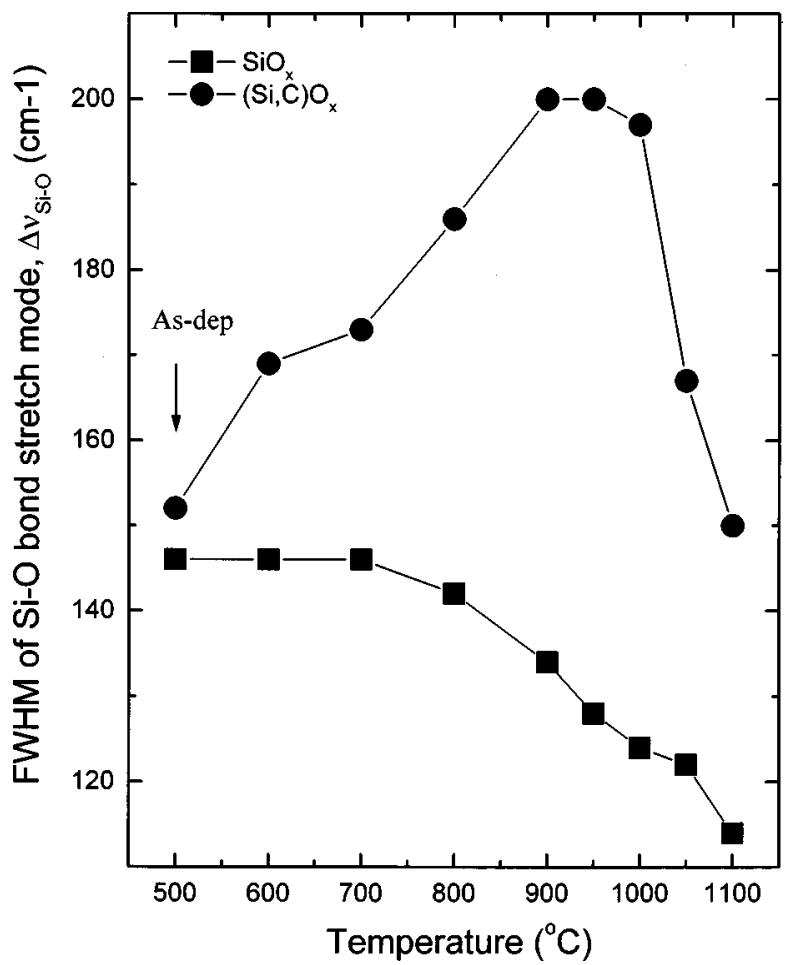

FIG. 9. FWHM, $\Delta \nu$, of the $\mathrm{Si}-\mathrm{O}$ bond stretch mode as a function of annealing temperature for $\mathrm{SiO}_{x},(x \sim 0.15)$ and $(\mathrm{Si}, \mathrm{C}) \mathrm{O}_{x},(x \sim 0.15$ and $\mathrm{C} \sim 10$ at. \%) thin films.

throughout the films. The size of the crystallites was approximately $4 \mathrm{~nm}$. The boxes in Fig. 8 outline typical Si crystallites. For annealing temperatures less than $1050{ }^{\circ} \mathrm{C}$, no crystalline products were imaged.

In summary, the significant bonding and morphology changes that occur between as-deposited films and films annealed at $1050{ }^{\circ} \mathrm{C}$ correspond to the formation of stoichiometric, structurally relaxed $\mathrm{SiO}_{2}$ regions and ordered $a-\mathrm{SiC}$ regions (from FTIR analysis), and nanocrystalline-Si regions (from Raman and TEM analysis).

\section{DISCUSSION}

To further correlate the trends in the data, and also to elucidate the extra feature in the FTIR spectra of the $(\mathrm{Si}, \mathrm{C}) \mathrm{O}_{x}$ films that has been attributed to $\mathrm{Si}-\mathrm{O}-\mathrm{C}$ arrangements, the full width at half maximum (FWHM), $\Delta \nu$, of the $\mathrm{Si}-\mathrm{O}$ and $\mathrm{Si}-\mathrm{C}$ bond stretch modes as a function of annealing temperature has been examined. As the FWHM of these modes decreases, the degree of structural ordering is increased. The FWHM of the $\mathrm{Si}-\mathrm{O}$ bond stretch mode as a function of annealing temperature for the $\mathrm{SiO}_{x}$ and $(\mathrm{Si}, \mathrm{C}) \mathrm{O}_{x}$ films is therefore plotted in Fig. 9. The FWHM of the Si-C bond stretching mode for the $\mathrm{SiC}_{x}$ and $(\mathrm{Si}, \mathrm{C}) \mathrm{O}_{x}$ films as a function of annealing temperature is plotted in Fig. 10. The size of the data points is the standard deviation in these measurements. As shown in Fig. 9, $\Delta \nu$ of the $\mathrm{Si}-\mathrm{O}$ bond stretch mode for the $\mathrm{SiO}_{x}$ films remains essentially constant upon annealing to $800{ }^{\circ} \mathrm{C}$, and then begins to decrease after $900{ }^{\circ} \mathrm{C}$. This decrease in $\Delta \nu$ after $900{ }^{\circ} \mathrm{C}$ annealing corre- 


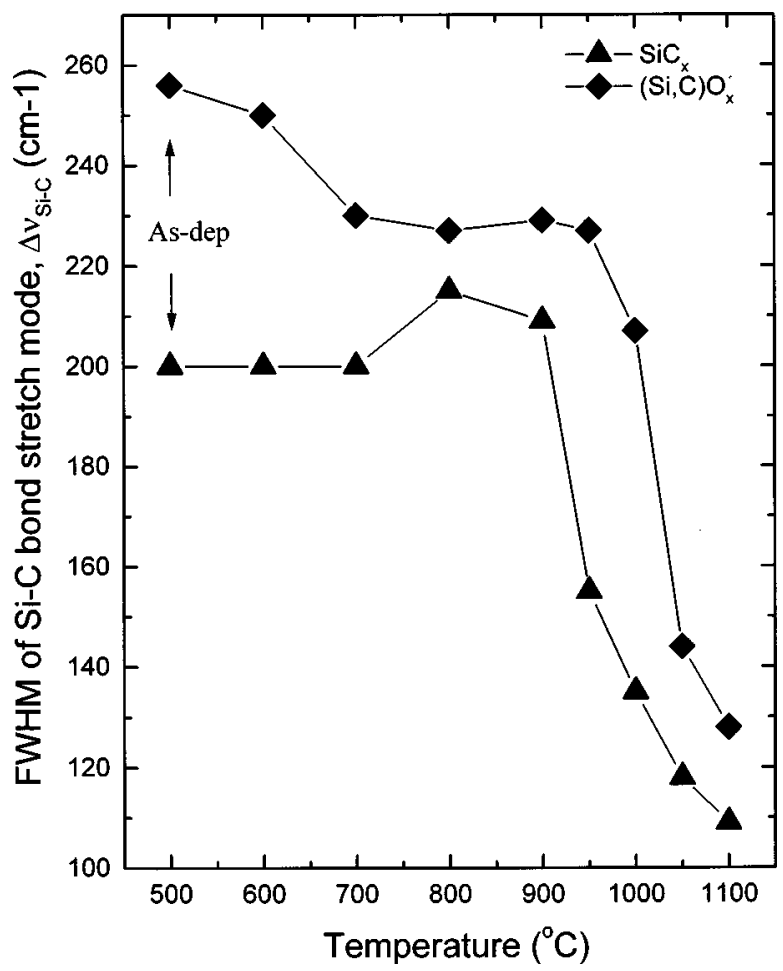

FIG. 10. FWHM, $\Delta \nu$, of the $\mathrm{Si}-\mathrm{C}$ bond stretch mode as a function of annealing temperature for $\mathrm{SiC}_{x},(x \sim 0.2)(\mathrm{SiC}) \mathrm{O}_{x},(x \sim 0.15)$ and $\mathrm{C} \sim 10$ at. \%) thin films.

lates (i) with the formation of stoichiometric and structurally relaxed $\mathrm{SiO}_{2}$ as determined by the shift in the $\mathrm{Si}-\mathrm{O}$ bond stretching peak position (Fig. 1), and (ii) with the formation of nanocrystalline-Si regions as determined through Raman spectra and TEM (Figs. 2 and 3). In contrast, $\Delta \nu$ of the $\mathrm{Si}-\mathrm{O}$ bond stretch mode for the $(\mathrm{Si}, \mathrm{C}) \mathrm{O}_{x}$ films increases significantly upon annealing to $900{ }^{\circ} \mathrm{C}$, remains constant between 900 and $1000{ }^{\circ} \mathrm{C}$, and then drops sharply after annealing to $1050{ }^{\circ} \mathrm{C}$. This trend correlates with results presented above in Figs. 6, 7, and 8. As previously mentioned, a shoulder on the high frequency side of the $\mathrm{Si}-\mathrm{O}$ stretch mode attributed to $\mathrm{Si}-\mathrm{O}-\mathrm{C}$ bonding was observed to emerge in the spectra of Fig. 6 between annealing temperatures of 900 and $1000{ }^{\circ} \mathrm{C}$, and then disappear at $1050{ }^{\circ} \mathrm{C}$. The disappearance of this shoulder after annealing to $1050{ }^{\circ} \mathrm{C}$ coincides with (i) a sharp decrease in $\Delta \nu$ of the $\mathrm{Si}-\mathrm{O}$ stretch mode in Fig. 9, (ii) the formation of stoichiometric and structurally relaxed $\mathrm{SiO}_{2}$ regions, as determined by the shift in the $\mathrm{Si}-\mathrm{O}$ bond stretch peak position in Fig. 6, and (iii) the formation of nanocrystalline-Si regions as determined through Raman spectra and TEM in Figs. 7 and 8, respectively.

Figure 10 shows $\Delta \nu$ for the $\mathrm{Si}-\mathrm{C}$ bond stretching mode in the $\mathrm{SiC}_{x}$ and $(\mathrm{Si}, \mathrm{C}) \mathrm{O}_{x}$ films as a function of annealing temperature. Again, the trends correlate with previous results. For the $\mathrm{SiC}_{x}$ films, a sharp decrease in $\Delta \nu$ of the $\mathrm{Si}-\mathrm{C}$ bond stretch mode occurs after annealing to $950{ }^{\circ} \mathrm{C}$, which coincides with (i) the formation of chemically ordered $a$-SiC regions in Fig. 4, and (ii) nanocrystalline-Si regions in Fig. 5. For the $(\mathrm{Si}, \mathrm{C}) \mathrm{O}_{x}$ films, a sharp decrease in $\Delta \nu$ of the $\mathrm{Si}-\mathrm{C}$

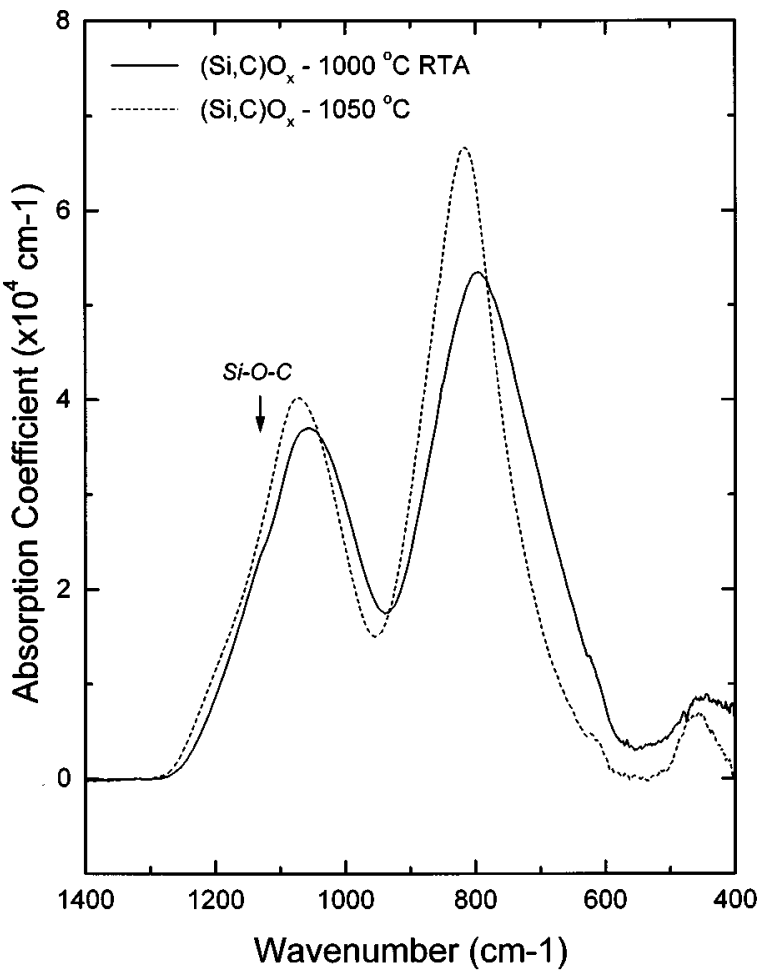

FIG. 11. FTIR absorption spectra of $(\mathrm{Si}, \mathrm{C}) \mathrm{O}_{x},(x \sim 0.15$ and $\mathrm{C} \sim 10$ at. \%) thin films after annealing to 1000 and $1050{ }^{\circ} \mathrm{C}$.

bond stretching mode does not occur until after annealing to $1050{ }^{\circ} \mathrm{C}$, which coincides with the elimination of $\mathrm{Si}-\mathrm{O}-\mathrm{C}$ bonding groups. This is also consistent with the formation of (i) stoichiometric, thermally relaxed $\mathrm{SiO}_{2}$ regions and ordered $a$-SiC regions in Fig. 6, and (ii) nanocrystalline-Si regions in Figs. 7 and 8.

Additional quantitative evidence for the elimination of $\mathrm{Si}-\mathrm{O}-\mathrm{C}$ bonding groups in the $(\mathrm{Si}, \mathrm{C}) \mathrm{O}_{x}$ films upon annealing to $1050{ }^{\circ} \mathrm{C}$ is shown in Figs. 11 and 12 . Figure 11 shows only the FTIR spectra of $(\mathrm{Si}, \mathrm{C}) \mathrm{O}_{x}$ films, $x \sim 0.15$ and $\mathrm{C} \sim 10$ at. $\%$ annealed at 1000 and $1050{ }^{\circ} \mathrm{C}$ (compare with Fig. 6). Figure 12 shows the corresponding first derivative spectra in Fig. 11. As shown in Fig. 11, a shoulder is evident at approximately $1125 \mathrm{~cm}^{-1}$ after annealing to $1000^{\circ} \mathrm{C}$, and is not present after annealing to $1050{ }^{\circ} \mathrm{C}$. The differentiated spectrum in Fig. 12 after annealing to $1000^{\circ} \mathrm{C}$ shows that the derivative decreases abruptly at $1125 \mathrm{~cm}^{-1}$ due to the shoulder on the high frequency side of the $\mathrm{Si}-\mathrm{O}$ bond stretch mode caused by $\mathrm{Si}-\mathrm{O}-\mathrm{C}$ bonding groups. After annealing to $1050{ }^{\circ} \mathrm{C}$, the shoulder is eliminated in Fig. 11 and the corresponding derivative spectrum in Fig. 12 is smooth.

We will now discuss how these results on bulk films analyzed in this study correlate with changes in interface bonding and chemistry observed to occur during the thermal oxidation of $\mathrm{SiC}$ and subsequent annealing of $\mathrm{SiC}-\mathrm{SiO}_{2}$ interfaces. Before doing this we will first consider the $\mathrm{SiO}_{x}$ films. Our results showed that at approximately $900{ }^{\circ} \mathrm{C}$ suboxide bonding was eliminated and the films separated into stoichiometric, thermally relaxed $\mathrm{SiO}_{2}$ regions and nanocrystalline-Si regions. These results are in accordance 


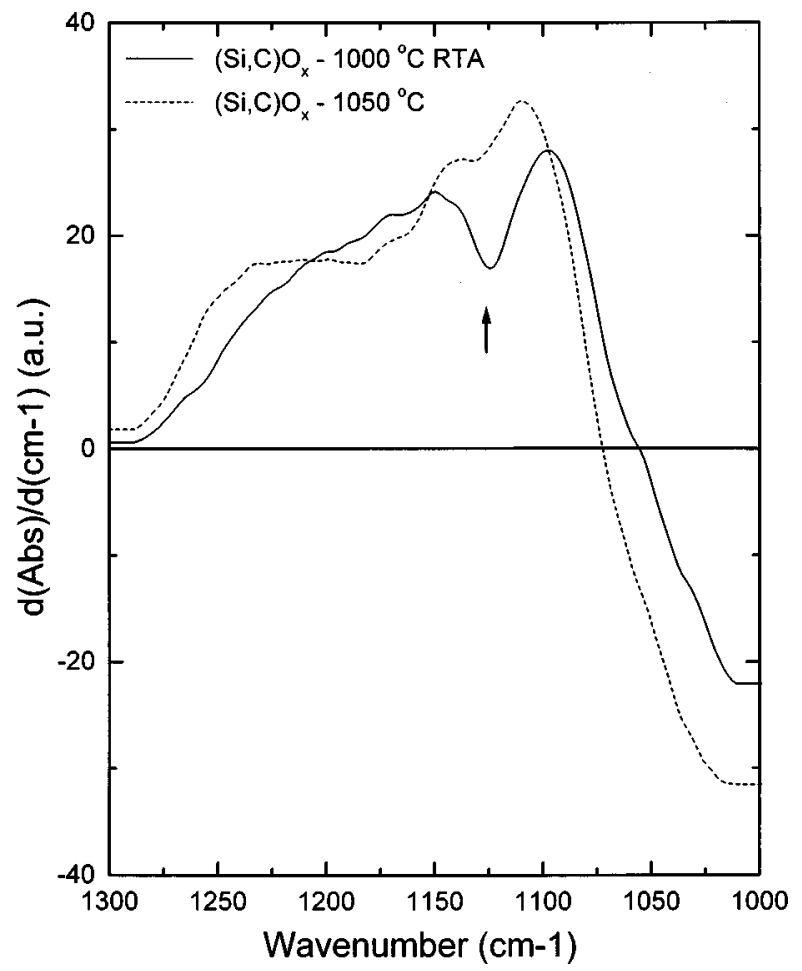

FIG. 12. First derivative FTIR absorption spectra of $(\mathrm{Si}, \mathrm{C}) \mathrm{O}_{x}, \quad(x \sim 0.15$ and $\mathrm{C} \sim 10$ at. \%) thin films after annealing to 1000 and $1050^{\circ} \mathrm{C}$.

with studies performed directly on $\mathrm{Si}-\mathrm{SiO}_{2}$ interfaces. For example, suboxide bonding at $\mathrm{Si}-\mathrm{SiO}_{2}$ interfaces before and after annealing at $900{ }^{\circ} \mathrm{C}$ has been studied by XPS, ${ }^{7,30,31}$ $\mathrm{AES},{ }^{13} \mathrm{TEM}^{5},{ }^{\mathrm{difference} x} \mathrm{x}$-ray diffraction, ${ }^{10}$ and more recently XPS using monochromatic synchrotron radiation. ${ }^{4}$ These studies have confirmed the reduction of excess suboxide bonding by annealing in an inert ambient at $900{ }^{\circ} \mathrm{C}$. In addition, the experiments described in Ref. 5 establish that growing an oxide at $900{ }^{\circ} \mathrm{C}$ is not equivalent to growth at $900{ }^{\circ} \mathrm{C}$ followed by annealing at the same temperature. The apparent saturation of annealing effects in $\mathrm{Si}-\mathrm{SiO}_{2}$ interfaces after $900{ }^{\circ} \mathrm{C}$ annealing suggests that the phase separation reaction observed in the deposited $\mathrm{SiO}_{x}$ thin films at $900{ }^{\circ} \mathrm{C}$, i.e., $\mathrm{SiO}_{x} \rightarrow \mathrm{SiO}_{2}+n c$ - $\mathrm{Si}$, also occurs at the crystal interface. However, there are two important differences in the effects that take place at the $\mathrm{Si}-\mathrm{SiO}_{2}$ interface. First, the separation is incomplete at the monolayer level, meaning the annealed $\mathrm{Si}-\mathrm{SiO}_{2}$ interfaces have a residual suboxide bonding on the order of a few monolayers. Second, there is no evidence for the formation of $n c$-Si. The separation reaction results in increased crystallization at the $\mathrm{Si}-\mathrm{SiO}_{2}$ interface, so that in place of the formation of nanocrystallites of $\mathrm{Si}, \mathrm{Si}$ derived form $\mathrm{SiO}_{x}$ regions is incorporated into the $\mathrm{Si}$ substrate.

Now turning to $\mathrm{SiC}-\mathrm{SiO}_{2}$ interfaces, observations based on the occurrence of $\mathrm{Si}-$ oxycarbide groups at the interface by XPS, ${ }^{14}$ and significant improvements in device performance by an oxidation/annealing sequence ${ }^{17}$ in which the oxidation is performed at a temperature in excess of $1025^{\circ} \mathrm{C}$, and the postoxidation anneal at $900{ }^{\circ} \mathrm{C}$ are interpreted as follows. Based on the alloy studies presented above which show that oxycarbide bonding is eliminated at approximately $1050{ }^{\circ} \mathrm{C}$, the requirement for a high temperature oxidation is to remove $\mathrm{Si}-\mathrm{O}-\mathrm{C}$ bonding groups that form at the boundary between $\mathrm{Si}$ surface atoms and the growing oxide layer. Since device fabrication is usually done on $\mathrm{Si}$ faces of $6 \mathrm{H}$ or $4 \mathrm{H}$ wafers, the annealing step at $900{ }^{\circ} \mathrm{C}$ then presumably performs the same function as at $\mathrm{Si}-\mathrm{SiO}_{2}$ interfaces, reducing suboxide bonding in interfacial transitions regions and smoothing the interface.

Finally, the results presented above on the thermochemical stability of silicon oxycarbide thin films deposited via chemical vapor deposition are in accordance with results in the literature on the characterization of silicon oxycarbide glasses prepared from sol-gel precursors. ${ }^{32,33}$

\section{CONCLUSIONS}

The thermal stability of silicon-oxygen-carbon alloy thin films $(\mathrm{Si}, \mathrm{C}) \mathrm{O}_{x}$ has been studied by a combination of FTIR spectroscopy, Raman scattering, and high-resolution TEM. Reference films of $\mathrm{SiO}_{x}$ and $\mathrm{SiC}_{x}$ were also prepared and analyzed. Results showed that for the $\mathrm{SiO}_{x}$ films, a structural/chemical transformation takes place at $900{ }^{\circ} \mathrm{C}$ in which the films separated into stoichiometric, thermally relaxed $\mathrm{SiO}_{2}$ and nanocrystalline- $\mathrm{Si}$ regions. For the $\mathrm{SiC}_{x}$ films, a structural/chemical transformation takes place at $950{ }^{\circ} \mathrm{C}$ in which the films separated into chemically ordered $a-\mathrm{SiC}$ and nanocrystalline-Si regions. In the $(\mathrm{Si}, \mathrm{C}) \mathrm{O}_{x}$ system, similar structural/chemical transformations take place at $1050{ }^{\circ} \mathrm{C}$, with the film separating into ordered $a$-SiC regions and stoichiometric, thermally relaxed $\mathrm{SiO}_{2}$, and nanocrystalline-Si regions. However a very important difference was noted for the $(\mathrm{Si}, \mathrm{C}) \mathrm{O}_{x}$ films. At temperatures of $900-1000{ }^{\circ} \mathrm{C}$ a $\mathrm{Si}-\mathrm{O}-\mathrm{C}$ bonding group was observed to form which in turn has been assumed to inhibit the phase separation process until the $\mathrm{Si}-\mathrm{O}-\mathrm{C}$ bonding group was eliminated at $1050{ }^{\circ} \mathrm{C}$. Important implications of this study towards $\mathrm{SiC}-\mathrm{SiO}_{2}$ interface processing are that oxidation must be performed above $1050{ }^{\circ} \mathrm{C}$ to ensure no oxycarbide bonding at the interface and that a $900{ }^{\circ} \mathrm{C}$ postoxidation anneal is necessary to reduce suboxide bonding and smooth the interface.

\section{ACKNOWLEDGMENTS}

This research has been supported in part by the Office of Naval Research and the Air Force Office of Scientific Research.

${ }^{1}$ F. J. Grunthaner and P. J. Grunthaner, Mater. Sci. Rep. 1, 69 (1986).

${ }^{2}$ J. Halbritter, J. Mater. Res. 3, 506 (1988).

${ }^{3}$ T. Hattori, CRC Crit. Rev. Solid State Mater. Sci. 20, 339 (1995).

${ }^{4}$ J. W. Kiester, J. E. Rowe, J. J. Kododzie, H. Niimi, H.-S. Tao, T. E. Madey, and G. Lucovsky, J. Vac. Sci. Technol. A (these proceedings).

${ }^{5}$ X. Chen and J. M. Gibson, Appl. Phys. Lett. 70, 1462 (1997).

${ }^{6}$ G. Lucovsky, A. Banerjee, H. Niimi, K. Koh, B. Hinds, C. Meyer, G. Lüpke, and H. Kurz, Appl. Surf. Sci. 117, 202 (1997).

${ }^{7}$ W. K. Choi, F. W. Poon, F. C. Loh, and K. L. Tan, J. Appl. Phys. 81, 7386 (1997)

${ }^{8}$ K. Ishikawa, Y. Uchiyama, H. Ogawa, and S. Fujimura, Appl. Surf. Sci. 117, 212 (1997). 
${ }^{9}$ N. Yasuda, S. Takagi, and A. Toriumi, Appl. Surf. Sci. 117, 216 (1997).

${ }^{10}$ N. Awaji, S. Ohkubo, T. Nakanishi, K. Takasaki, and S. Komiya, Appl. Surf. Sci. 117, 221 (1997).

${ }^{11}$ A. Toriumi, H. Satake, N. Yasuda, and T. Tanamoto, Appl. Surf. Sci. 117, 230 (1997).

${ }^{12}$ T. Sakoda, M. Matsumura, and Y. Nishioka, Appl. Surf. Sci. 117, 241 (1997).

${ }^{13}$ G. Lucovsky, A. Banerjee, B. Hinds, B. Claflin, K. Koh, and H. Yang, J. Vac. Sci. Technol. B 15, 1074 (1997).

${ }^{14}$ B. Hornetz, H-J. Michel, and J. Halbritter, J. Mater. Res. 9, 3088 (1994).

${ }^{15}$ M. I. Chaudrhy, J. Mater. Res. 4, 404 (1989).

${ }^{16}$ C. Önneby and C. G. Pantano, J. Vac. Sci. Technol. A 15, 1597 (1997).

${ }^{17}$ L. Lipkin and J. W. Palmour, J. Electron. Mater. 25, 909 (1996).

${ }^{18}$ K. I. Luthra, J. Am. Ceram. Soc. 74, 1095 (1991).

${ }^{19}$ D. V. Tsu, G. Lucovsky, and B. N. Davidson, Phys. Rev. B 40, 1795 (1989).

${ }^{20}$ B. J. Hinds, F. Wang, D. M. Wolfe, C. L. Hinkle, and G. Lucovsky, J. Non-Cryst. Solids 227, 507 (1998).

${ }^{21}$ G. Lucovsky, J. Non-Cryst. Solids 227, 1 (1998).

${ }^{22}$ G. Lucovsky, D. V. Tsu, R. A. Rudder, and R. J. Markunas, in Thin film Processes II, edited by J. L. Vossen and W. Kern (Academic, San Diego, 1991), pp. 565-619.
${ }^{23}$ D. M. Wolfe, F. Wang, B. J. Hinds, and G. Lucovsky, Mater. Res. Soc. Symp. Proc. 483, 203 (1998).

${ }^{24}$ G. Lucovsky, J. Yang, S. S. Chao, J. E. Tyler, and W. Czubatyj, Phys. Rev. B 28, 3224 (1983).

${ }^{25} \mathrm{G}$. Socrates, Infrared Characteristic Group Frequencies, 2nd ed. (Wiley, Chichester, 1994), Chap. 18.

${ }^{26}$ H. Reubel, B. Schroeder, W. Fuhs, J. Krauskopf, T. Rupp, and K. Bethge, Phys. Status Solidi B 139, 131 (1987).

${ }^{27}$ D. W. Feldman, J. H. Parker, Jr., W.J. Choyke, and L. Patrick, Phys. Rev. 173, 787 (1968).

${ }^{28}$ L. J. Bellamy, The Infrared Spectra of Complex Molecules (Chapman and Hall, London, 1975), Chap. 20.

${ }^{29}$ A. L. Smith, The Analytical Chemistry of Silicones (Wiley, New York, 1991), p. 336.

${ }^{30}$ G. Hollinger and F. J. Himpsel, Appl. Phys. Lett. 44, 93 (1984).

${ }^{31}$ P. J. Grunthaner, M. H. Hecht, F. J. Grunthaner, and N. M. Johnson, J. Appl. Phys. 61, 629 (1987).

${ }^{32}$ H. Zhang and C. G. Pantano, J. Am. Ceram. Soc. 73, 958 (1990).

${ }^{33}$ G. D. Sorarù, G. D'Andrea, R. Campostrini, F. Babonneau, and G. Mariotto, J. Am. Ceram. Soc. 78, 379 (1995). 